\title{
Chapter 13 \\ Remediation of Paddy Soil Contaminated \\ by Radiocesium in Iitate Village \\ in Fukushima Prefecture
}

\author{
Masaru Mizoguchi
}

\begin{abstract}
Paddy soil freezes during winter in Iitate village. The frozen soil is as hard as asphalt, and local farmers can easily peel a plate of frozen soil using an agricultural machine. The radiation level in the ground surface was demonstrated to reduce from 1.28 to $0.16 \mu \mathrm{Sv} / \mathrm{h}$ by stripping the frozen soil in field experiments. In this chapter, two remediation methods have been introduced and the collaboration between researchers, volunteers, and farmers in Iitate Village has been discussed.
\end{abstract}

Keywords Decontamination • Frozen soil • Rotary weeding method $\bullet$ Stripping method

\subsection{Introduction}

The radiocesium released from the Fukushima Daiichi nuclear power plant accumulates mainly within the top $5 \mathrm{~cm}$ of the soil surface. However, the state of the ground surface differs depending on the land use; therefore, radiocesium is distributed heterogeneously in space and depth. Thus, the efficient decontamination of contaminated soil demands the stripping of topsoil, which depends on the state of the farmland. The group known as the "Resurrection of Fukushima" has been independently developing soil decontamination methods in collaboration with the Agriculture Committee of Iitate village, although the Ministry of the Environment and the Ministry of Agriculture, Forestry, and Fisheries are also investigating various

\footnotetext{
M. Mizoguchi $(\bowtie)$

Graduate School of Agricultural and Life Sciences, The University of Tokyo,

1-1-1 Yayoi, Bunkyo-ku, Tokyo 113-8657, Japan

e-mail:amizo@mail.ecc.u-tokyo.ac.jp
} 
decontamination methods. In this chapter, two methods developed by the group are described. In addition, the collaboration between researchers, volunteers, and farmers to decontaminate farmland has been discussed.

\subsection{The "Resurrection of Fukushima" Group}

This group is a volunteer organization, which aims to reconstruct the lives and the industries of the area that were severely damaged by the Great East Japan Earthquake and the accident at the Fukushima Daiichi nuclear power plant. The group has been conducting activities in the disaster-affected areas with a central focus on the Fukushima Prefecture. The group established a base of activities in Iitate village in June 2011, and it has advanced various projects aimed at the resurrection/reconstitution of the area while finding the best way of working with the affected people.

The major projects that are now under development are (1) conducting thorough radiation measurements and creating radiation dose survey maps; (2) decontamination demonstration experiments in houses, agricultural land, and forests; (3) care of affected people by teams of professionals including medical doctors; (4) publicizing the real lives of people in the area affected by the nuclear power plant accident through information communication technologies. The activities and results of the projects are available for public inspection on their current website (Resurrection of Fukushima 2012a).

\subsection{Distribution of Paddy Soil Contaminated by Radiocesium in Iitate Village}

There are many small paddy fields between the forests that comprise $74 \%$ of the Iitate village. Therefore, the soil and weather (such as the temperature and wind speed) in the paddy fields of the village differ depending on their location. On the other hand, because farmers in this district generally plow the paddy before winter, the paddy surfaces are uneven rather than flat. Figure 13.1 shows the distribution of radiocesium in paddy soil in 19 districts of Iitate village, which were measured by the group between January and March 2012 (Resurrection of Fukushima 2012b). Although radiocesium has been reported to accumulate near the ground surface (Shiozawa et al. 2011), Fig. 13.1 shows that the distribution of radiocesium was different in each place and it reached deeper levels in some places. This is because the surface state was different in each paddy field. In some places, summer grass was flourishing (Fig. 13.2) because farmers did not use their paddy in 2011, whereas wild boars had been digging holes in another paddy (Fig. 13.3). For efficient decontamination, it is necessary to create a pollution map and to ensure that the surface of the paddy is flat before decontamination. 


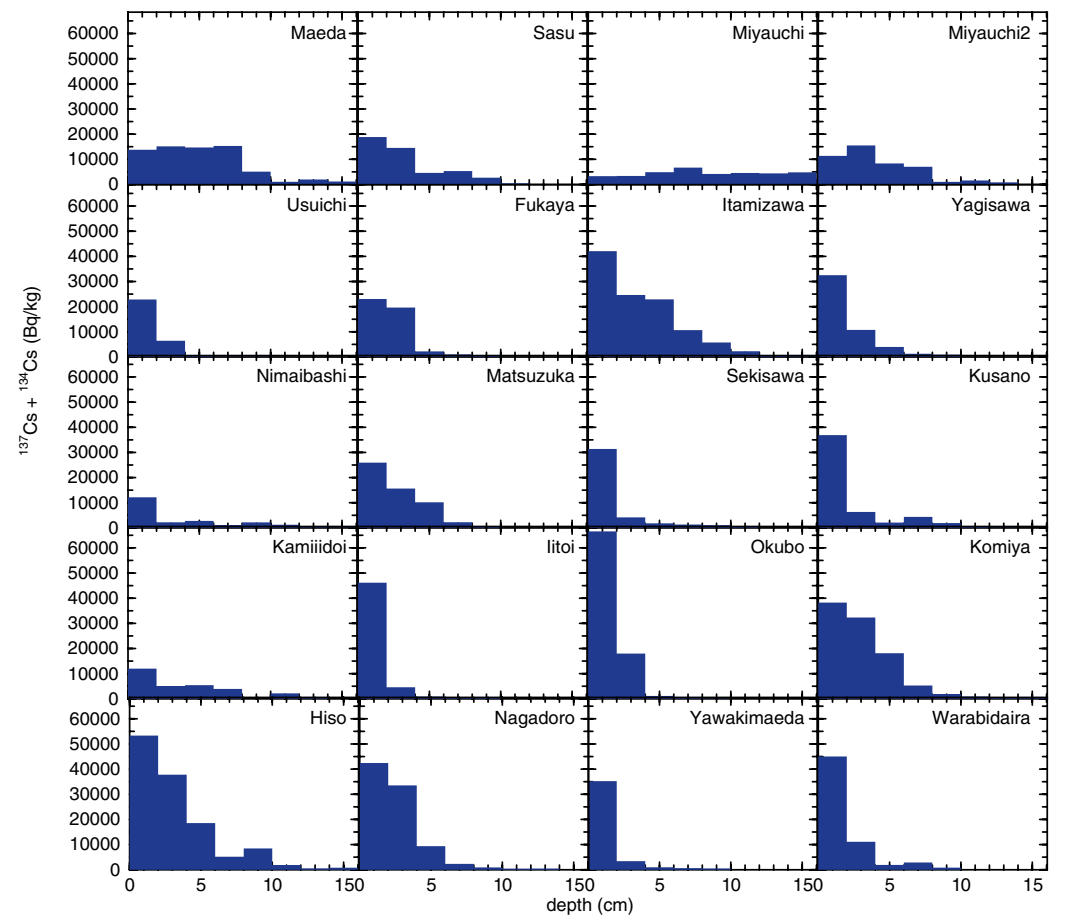

Fig. 13.1 Distribution of radiocesium in paddy soil from 19 regions in Iitate village (Resurrection of Fukushima 2012b)

Fig. 13.2 Summer grass growing on a paddy

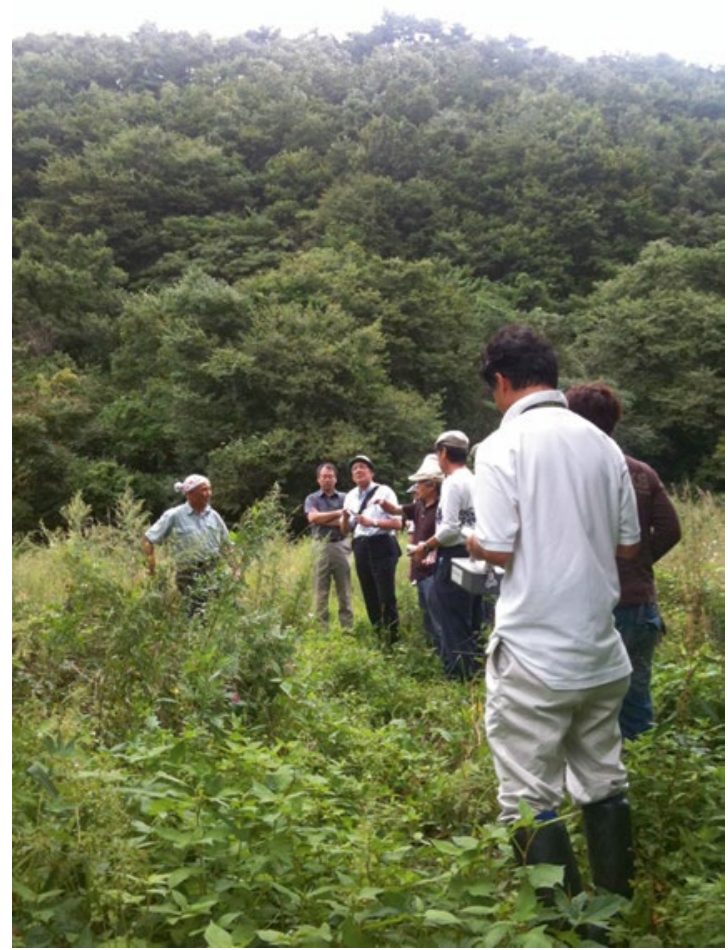


Fig. 13.3 Paddy destructed by wild boar

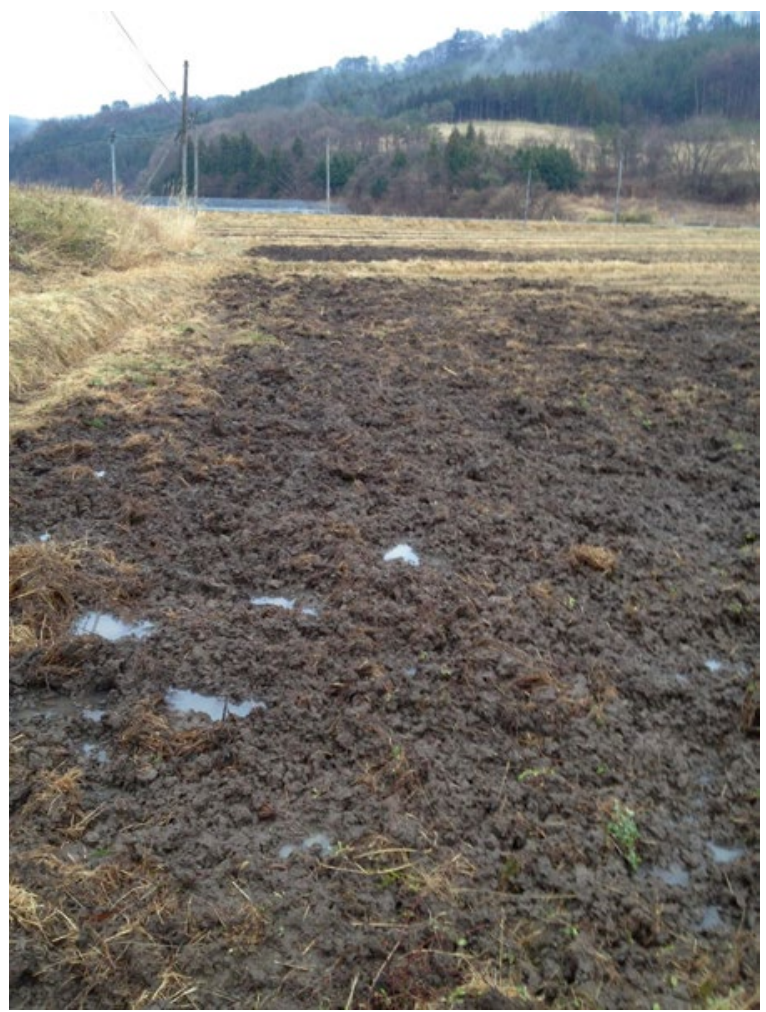

\subsection{Decontamination by Stripping Frozen Soil}

The soil freezes during the winter in litate village. Figure 13.4 shows the changes in the soil temperature and soil moisture level (volumetric water content) at depths of 5, 10, and $15 \mathrm{~cm}$. The accuracies of the soil temperature and moisture measurements were $0.1^{\circ} \mathrm{C}$ and $0.03 \mathrm{~m}^{3} / \mathrm{m}^{3}$, respectively. The soil temperatures at a depth of $5 \mathrm{~cm}$ reached $0^{\circ} \mathrm{C}$, whereas the soil moisture level at the same depth fell to $0.2 \mathrm{~m}^{3} / \mathrm{m}^{3}$ at $6: 00$ on January 1st, 2012. This indicated that the soil froze to a depth of at least $5 \mathrm{~cm}$ on January 1st, 2012.

The frozen soil is as hard as asphalt and farmers could easily strip the frozen soil using a backhoe, which farmers normally possess (Fig. 13.5). In field experiments, we confirmed that the level of radiation in the ground surface reduced from 1.28 to $0.16 \mu \mathrm{Sv} / \mathrm{h}$ on stripping the frozen paddy soil (Fig. 13.6). The radioactivity in the unfrozen soil after stripping was $2,670 \mathrm{~Bq} / \mathrm{kg}$, whereas that in the stripped frozen soil was $23,760 \mathrm{~Bq} / \mathrm{kg}$. This dramatic reduction in the radioactivity level indicated that the radiocesium in the topsoil could be removed by stripping the 
13 Remediation of Paddy Soil Contaminated by Radiocesium in Iitate Village...

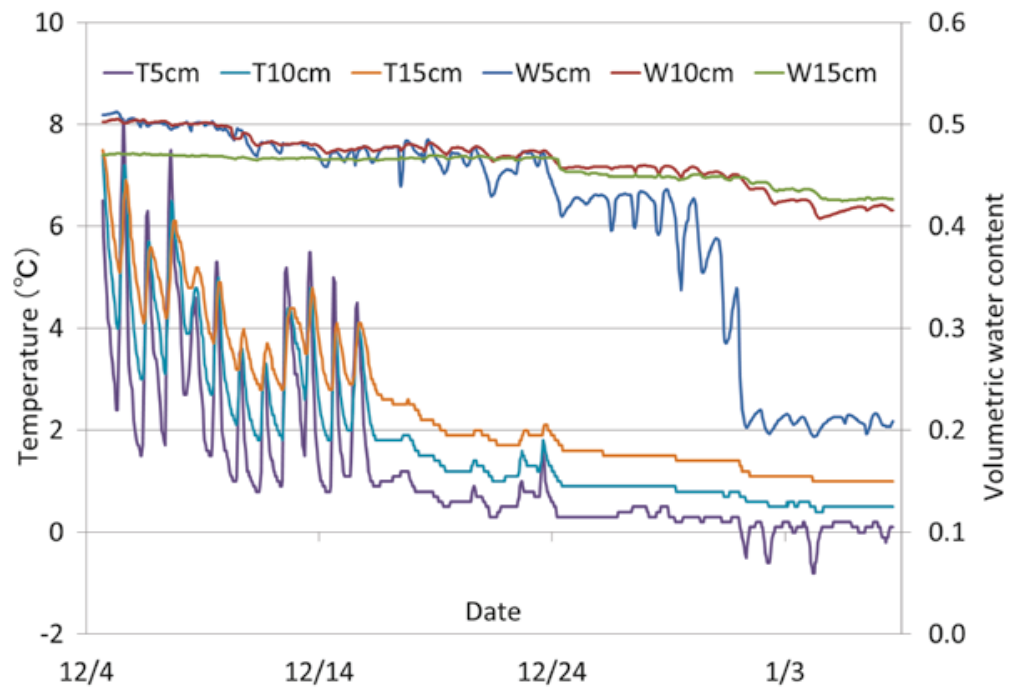

Fig. 13.4 Changes in the soil temperature and soil moisture level at depths of 5, 10, and $15 \mathrm{~cm}$ in a paddy in Iitate village

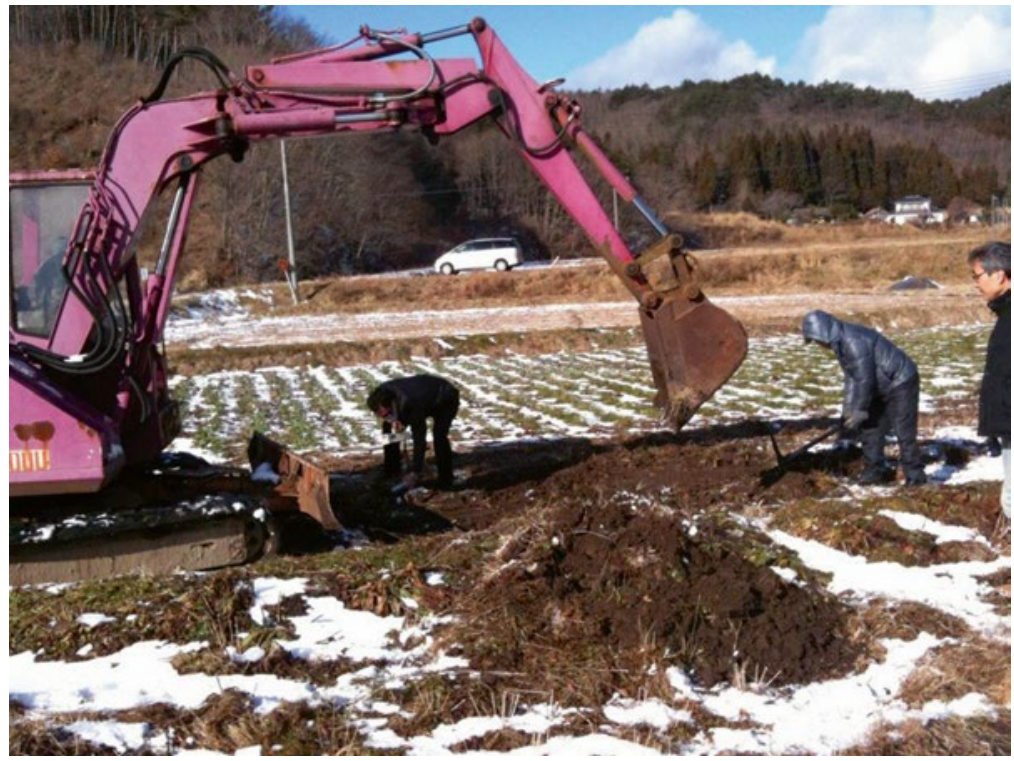

Fig. 13.5 Stripping the frozen soil using a backhoe by a local farmer on January 8th, 2012 


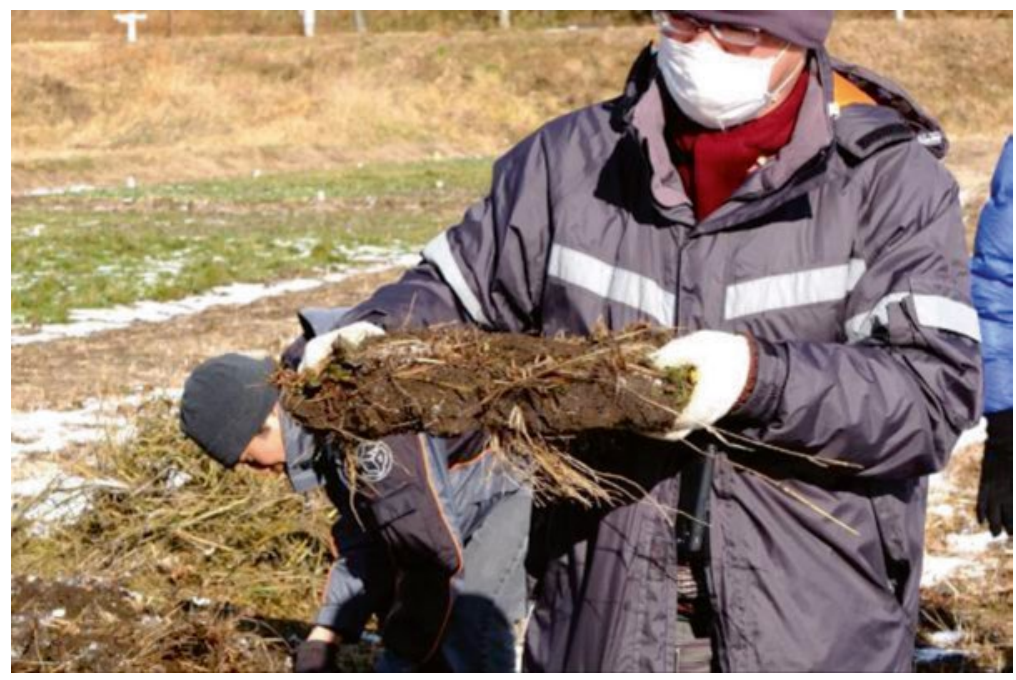

Fig. 13.6 The frozen soil stripped using a backhoe formed a plate-shaped mass

frozen soil. This simple method exploits a natural process. Therefore, it was possible to reduce the risk exposure for workers engaged in decontamination work. We also confirmed that the radiation dose could be reduced further if the frozen soil is removed carefully without turning it upside down.

The difficulty with this method was predicting the timing of stripping frozen soil. This was because more fertile soil was lost if a thicker layer of frozen soil was stripped. Therefore, it was necessary to predict the optimum thickness of frozen soil before stripping. This was achieved using a hand-made freezing depth gauge. Figure 13.7 shows a test tube containing an aqueous solution of methylene blue that was buried in the field. The thickness of the frozen soil matched the thickness of the clear ice. It was also possible to estimate the thickness of the frozen soil from the air temperature in the field. However, because this estimation method is complex, it has been described in the appendix.

In Iitate village, the topsoil on some farmlands contains radiocesium mixed with the subsoil. Thus, the topsoil stripping method cannot be used for these farmlands. However, if the clay particles that fixed radiocesium are accumulated by puddling the paddy soil before winter, radiocesium can be removed effectively by only stripping the frozen soil during winter.

The soil moisture moves into the frozen soil during the freezing process on farmlands. Therefore, the frozen soil stripping method can also be used with relatively dry soil. However, the frozen soil on pasture land is not hard because of its low bulk density. In this case, we must use a heavy machine to compress the topsoil before winter to increase the efficiency of stripping frozen soil. 
Fig. 13.7 A hand-made freezing depth gauge containing an aqueous solution of methylene blue

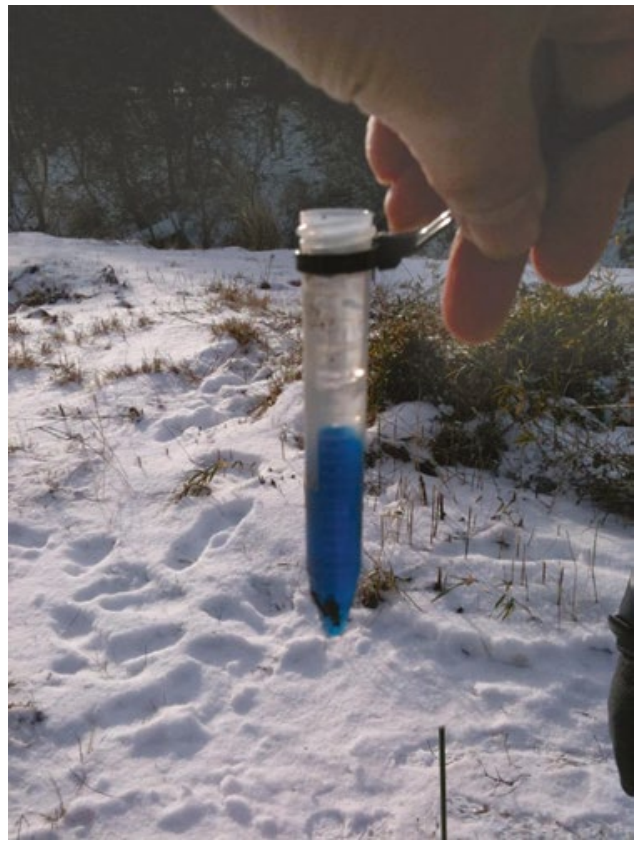

\subsection{Decontamination Method Using a Rotary Weeding Machine}

Rotary weeding machines (intertillage weeding machine) are used in Japan for weeding after planting. In April 2012, we irrigated a paddy with water to a depth of approximately $5 \mathrm{~cm}$ and agitated the soil surface using a rotary weeding machine. The muddy water was swept out into a drainage ditch using a tennis court brush (Fig. 13.8). We repeated this operation thrice and measured the amount of radiocesium in soil. Figure 13.9 shows the radiocesium profiles before/after rotary weeding. The results showed that approximately $80 \%$ of the radiocesium was removed from the paddy using this method.

The problems that remained were the efficiency of the work and the treatment of the muddy water. This experiment was performed manually. However, given the vast area of farmland that needs to be decontaminated, we will require a machine to improve the efficiency of work. In the muddy water treatment, we swept the muddy water into a drainage ditch that measured $1 \mathrm{~m}$ deep and $50 \mathrm{~cm}$ wide, which was dug around the paddy field. After 3 months, the muddy water infiltrated into the soil and remained as a dry clay layer on the surface of the ditch. Figure 13.10 shows the concentration of radiocesium in the soil surrounding the drainage ditch (Mizoguchi 2012). The radiocesium had penetrated to a maximum depth of 6-7 cm 


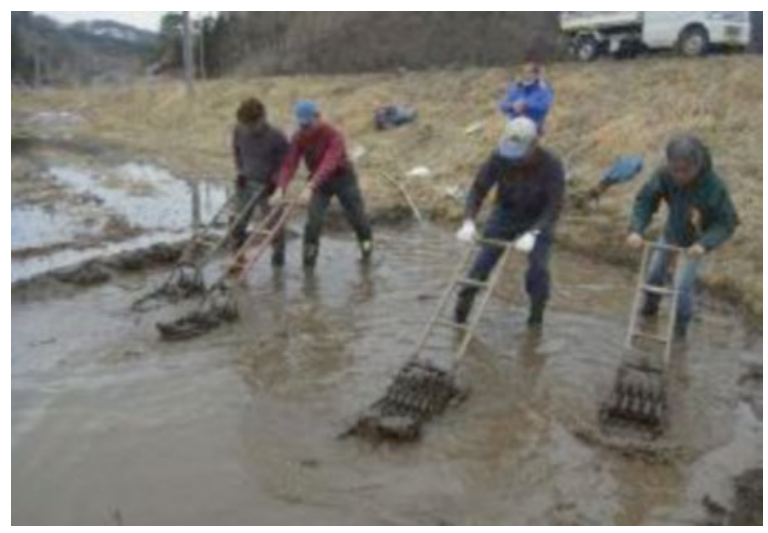

Fig. 13.8 The rotary weeding method tested by a volunteer group (Resurrection of Fukushima 2012c)
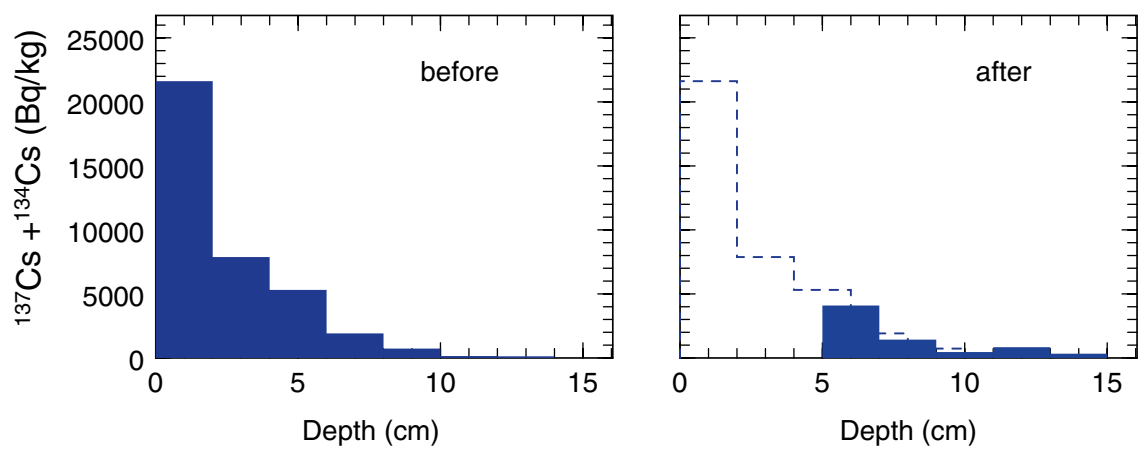

Fig. 13.9 The radiocesium profiles before/after rotary weeding (Resurrection of Fukushima 2012c)

in the soils at the bottom and on the walls of the ditch. Thus, the drainage ditch had a filtration capacity (Yahata 1980) and it effectively trapped clay particles that contained radiocesium.

Another possible muddy water treatment is to gather muddy water in a downstream paddy and keep the paddy flooded to attenuate the radiation dose from the ground surface. The frozen soil can be stripped in winter after the natural infiltration of water just before winter. 

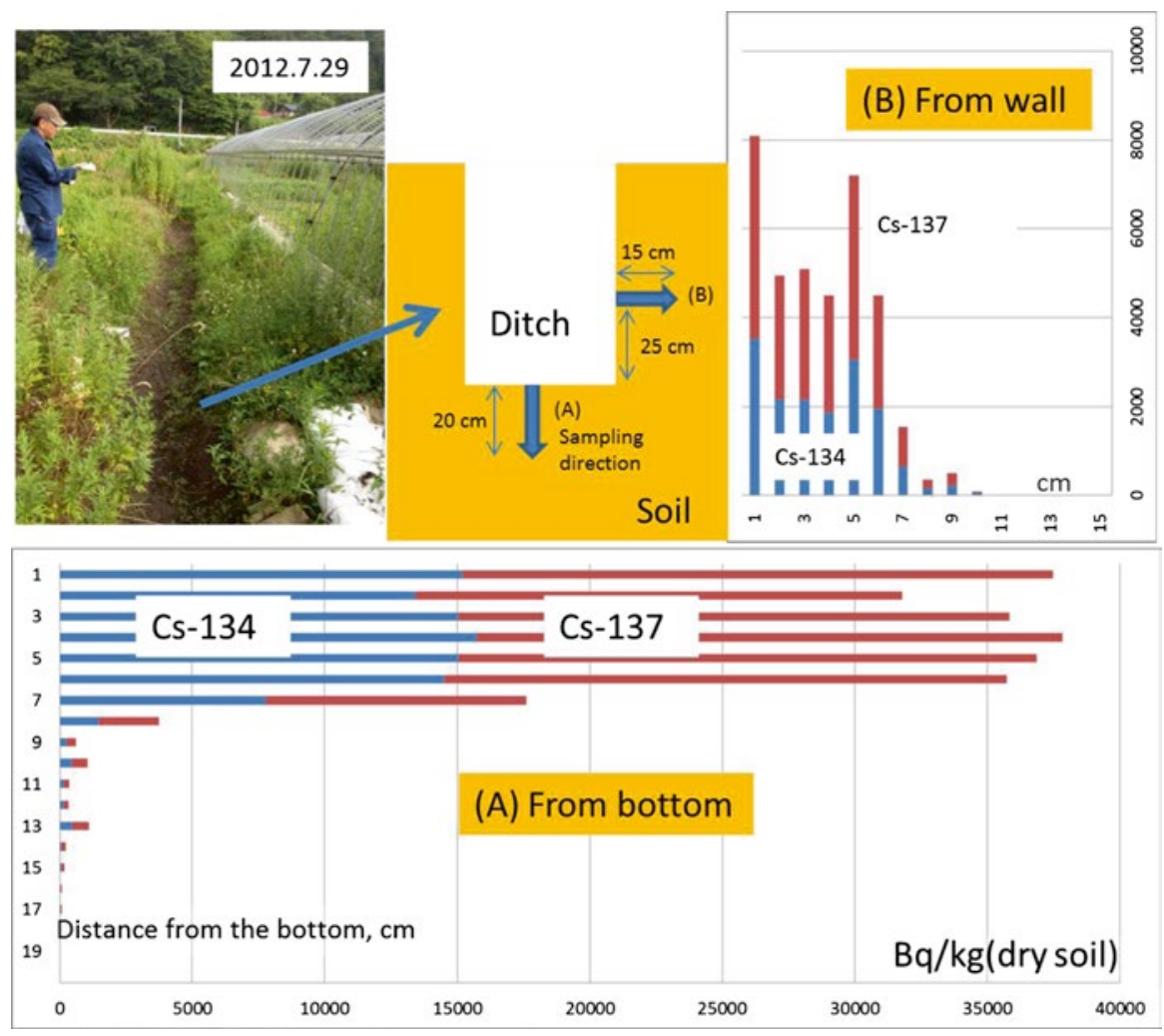

Fig. 13.10 Concentration of radiocesium in the soil surrounding the drainage ditch (Mizoguchi 2012)

\subsection{Radiation Dose Reduction Method Based on Soil Cover}

The treatment of the removed contaminated soil is a big challenge. It is difficult to find a waste disposal site in Iitate village. Even if one can be located, the capacity of the disposal site is insufficient. There is also a risk of environmental contamination with radiocesium while carrying the waste soil to the waste disposal site. Thus, it might be practical to bury the contaminated soil in a hole in a corner of the paddy field. A laboratory experiment showed that a $50-\mathrm{cm}$ thick layer of soil could reduce the radiation dose to approximately 1/100 (Miyazaki 2012).

However, the problem with this method will be preventing the leakage of radiocesium from contaminated soil, which depended on soil type, soil moisture, and groundwater level. If there is sand or gravel in the lower layer of the paddy, it is necessary to dig a trench that is shallower than the layer. Assuming that we need to bury the top 5-10 cm layer of the surface soil at a 1-m depth, the burial area have to be approximately $10 \%$ of the paddy field area.

Radiocesium is fixed by weathered micas, which are clay minerals found in the typical soils distributed in the Iitate village area. After radiocesium is fixed by these 
clay minerals, it moves in the soil together with the clay particles, which are trapped by the filtration capacity of the soil. The radiocesium penetrated into a 6-7 cm layer of soil around the drainage ditch (Fig. 13.10). Thus, we will be able to reduce the radiation dose from the ground surface by covering the ditch with fresh soil.

From the perspective of soil physics, the best method is to bury the waste soil containing radiocesium in a hole at the corner of the paddy field. However, in order to convince the neighboring residents about the safety of this method of waste soil treatment, it is necessary to develop a method for monitoring the radiation in the soil around the waste soil. It is also necessary to demonstrate that the clay particles never flow into the downstream basin using a simulation based on the theory of soil physics in a condition of variable groundwater levels.

\subsection{Environmental Monitoring in the Village}

After decontaminating the paddy field, we need to evaluate the effectiveness of this decontamination procedure. In this evaluation, it is necessary to continuously monitor the soil radiation at important points (hotspots). In particular, it is important to observe the relationship between the radiation dose and the weather, particularly the precipitation and wind. It is also important to observe the relationship between precipitation and runoff/turbidity of rivers. However, radiation meters are too expensive for the general public. Thus, there is a need for an economical radiation dose sensor that provides relatively good value. Fortunately, a volunteer group has recently developed a Pocket Radiation Sensor in response to this need (the nonprofit project "radiation-watch.org," 2011).

I have also been developing a field monitoring system (FMS) for quasi-real-time data collection in a remote agricultural field in Asia (Mizoguchi 2011). After adding this new radiation sensor to FMS, in situ soil monitoring was initiated in Iitate Village. Figure 13.11 shows a comparison of the radiation measurements and images captured in a garden, a forest, and a deforested area from the autumn to the winter. The radiation levels fluctuated daily, particularly in the house, but they declined after January 20 when snow started to cover the ground. This showed that snow prevented radiation being emitted from the ground. In addition, we also collected a great deal of valuable radiation data using FMS. The preliminary comparisons of the radiation and meteorological data showed that the radiation levels tended to be higher on fine days with low humidity.

\subsection{Conclusion: The Roles of Researchers in Society}

Decontamination of farmland is the biggest challenge faced in agricultural engineering. There are differences in our positions in the nation and in organizations, but researchers are required to make a rapid response with many responsibilities. Radioactivity is an invisible opponent. Therefore, the risk of exposing young people in the Iitate village fields cannot be taken. However, senior volunteers in their 70s are working vigorously 


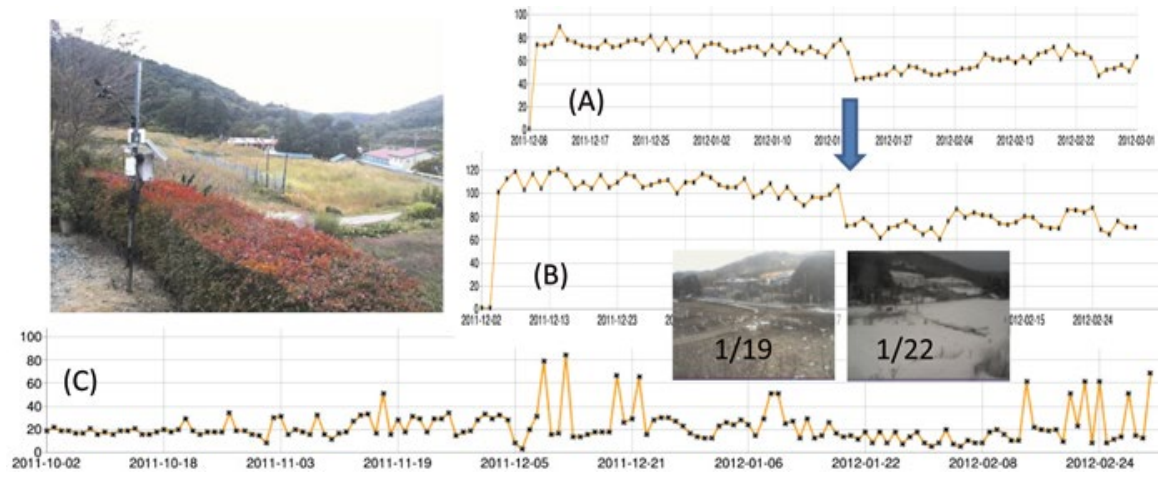

Fig. 13.11 Comparison of the radiation levels in three FMS sites: a garden, a forest, and a deforested area in Iitate village

in the fields each weekend. Their activities are changing the roles of researchers in our society. Beyond the confines of our specific disciplines, we must confront common challenges such as the decontamination of farmland with flexibility, depending on the situation. At present, we must question the identity of researchers in Japan.

Acknowledgments All field experiments were conducted with the cooperation of Mr. Muneo Kanno, Agriculture Committee in Iitate village, and members of the "Resurrection of Fukushima" (Representative: Dr Yoichi Tao). I express my sincere gratitude to them for their contribution. In addition, I thank the agricultural engineering team for reconstructing Fukushima at the University of Tokyo (Representative: Prof. Naritaka Kubo) and the Early return to village project at the Meiji University (Representative: Prof. Kosuke Noborio) for their assistance. Each FMS system was donated by Decagon Devices, Inc., AINEX Co., Ltd, and X-Ability Co., Ltd. through The Japanese Society of Irrigation, Drainage, and Rural Engineering (JSIDRE).

\section{Appendix: Equation for Estimating the Frozen Soil Depth Based on the Air Temperature}

Assuming that the temperature of the freezing front is a constant $0^{\circ} \mathrm{C}$ and there is a linear change from the ground surface to the freezing front, the heat balance of the freezing front can be expressed using the following differential equation:

$$
k \frac{T}{x}=\theta L \frac{d x}{d t}
$$

where $\mathrm{T}=$ temperature at the ground surface, $\mathrm{x}=$ the frost depth, $\mathrm{k}=$ the thermal conductivity of frozen soil, $\theta=$ volumetric water content of frozen soil, $\mathrm{L}=$ latent heat of freezing, and $t=$ time. In a case without $\theta$, this is known as the Stephan equation. This equation can be solved easily by separating the variables, where the frost depth is expressed using the following equation.

$$
\frac{k}{\theta L} \int T d t=\frac{x^{2}}{2}
$$




$$
x=\sqrt{\frac{2 k}{\theta L} \int T d t}
$$

If we introduce the freezing index $\mathrm{F}$, which is defined as $F=\int T d t$, the frost depth $\mathrm{x}$ is given as follows:

$$
x=\sqrt{\frac{2 k}{\theta L} F}
$$

where $\mathrm{k}$ and $\theta$ are physical properties of the frozen soil, and $\mathrm{L}$ is a constant. Therefore, the frost depth can be estimated as the square root of the freezing index F.

Theoretically, it is necessary to obtain $\mathrm{F}$ based on the ground surface temperature T. However, if we use the air temperature as a substitute for the ground surface temperature, the frost depth can be estimated from the air temperature data alone in the field using an empirical parameter $\alpha$.

$$
x=\alpha \sqrt{F}
$$

Open Access This article is distributed under the terms of the Creative Commons Attribution Noncommercial License which permits any noncommercial use, distribution, and reproduction in any medium, provided the original author(s) and source are credited.

\section{References}

Miyazaki T (2012) Radiation damping effect of cesium by soil, towards the reconstruction of agriculture, forestry and fisheries from the Great East Japan Earthquake. Association of Japanese Agricultural Science Societies, p 21. http://www.ajass.jp/image/recom2012.1.13.pd->http://www.ajass.jp/image/recom2012.1.13.pd\#page=25

Mizoguchi M (2011) Field Monitoring System (FMS). http://www.iai.ga.a.u-tokyo.ac.jp/mizo/ FMS.html

Mizoguchi M (2012) New approach for decontamination of farmland in Iitate village. Trends Sci 17(10):52-56, http://www.h4.dion.ne.jp/ jssf/text/doukousp/2012-10.html

Radiation-Watch.org (2011) http://www.radiation-watch.org/

Resurrection of Fukushima (2012a) http://www.fukushima-saisei.jp/index_en.html

Resurrection of Fukushima (2012b) Activity report of resurrection of Fukushima. http://www. fukushima-saisei.jp/report201203_en.html

Resurrection of Fukushima (2012c) Activity report of resurrection of Fukushima. http://www. fukushima-saisei.jp/report201204_en.html

Shiozawa S, Tanoi K, Nemoto K, Yoshida S, Nishida K, Hashimoto K, Sakurai K, Nakanishi T, Nihei N, Yuji O (2011) Vertical concentration profiles of radioactive cesium and convective velocity in soil in a paddy field in Fukushima. Radioisotopes 60:323-328

Yahata T (1980) Matters related to the filtering function. In: Soil physics, 3rd edn. University of Tokyo Press, Tokyo, pp 142-156 